This article was downloaded by: [informa internal users]

On: 4 December 2009

Access details: Access Details: [subscription number 755239602]

Publisher Taylor \& Francis

Informa Ltd Registered in England and Wales Registered Number: 1072954 Registered office: Mortimer House, 3741 Mortimer Street, London W1T 3JH, UK

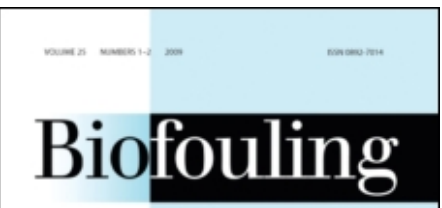

\title{
Biofouling
}

Publication details, including instructions for authors and subscription information: http://www-

intra.informaworld.com/smpp/title $\sim$ content=t713454511

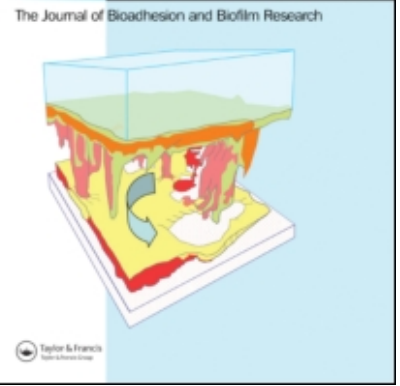

\section{Capsular polysaccharides of cultured phototrophic biofilms}

F. Di Pippo a ; A. Bohn b; R. Congestri a; R. De Philippis ${ }^{\text {; }}$; P. Albertano ${ }^{a}$

${ }^{a}$ Department of Biology, University of Rome 'Tor Vergata', Rome, Italy ${ }^{b}$ Instituto de Tecnologia Química e Biológica, Universidade Nova de Lisboa, Oeiras, Portugal c Department of Agricultural

Biotechnology, University of Florence, Florence, Italy

First published on: 20 April 2009

To cite this Article Di Pippo, F., Bohn, A., Congestri, R., De Philippis, R. and Albertano, P.(2009) 'Capsular polysaccharides of cultured phototrophic biofilms', Biofouling, 25: 6, 495 - 504, First published on: 20 April 2009 (iFirst)

To link to this Article: DOI: 10.1080/08927010902914037

URL: http://dx.doi.org/10.1080/08927010902914037

\section{PLEASE SCROLL DOWN FOR ARTICLE}

Full terms and conditions of use: http://www-intra.informaworld.com/terms-and-conditions-of-access.pdf

This article may be used for research, teaching and private study purposes. Any substantial or systematic reproduction, re-distribution, re-selling, loan or sub-licensing, systematic supply or distribution in any form to anyone is expressly forbidden.

The publisher does not give any warranty express or implied or make any representation that the contents will be complete or accurate or up to date. The accuracy of any instructions, formulae and drug doses should be independently verified with primary sources. The publisher shall not be liable for any loss, actions, claims, proceedings, demand or costs or damages whatsoever or howsoever caused arising directly or indirectly in connection with or arising out of the use of this material. 


\title{
Capsular polysaccharides of cultured phototrophic biofilms
}

\author{
F. Di Pippo ${ }^{\mathrm{a}}$, A. Bohn ${ }^{\mathrm{b}}$, R. Congestri ${ }^{\mathrm{a}}$, R. De Philippis ${ }^{\mathrm{c}}$ and P. Albertano ${ }^{\mathrm{a} *}$ \\ ${ }^{a}$ Department of Biology, University of Rome 'Tor Vergata', Rome, Italy; ${ }^{b}$ Instituto de Tecnologia Química e Biológica, \\ Universidade Nova de Lisboa, Oeiras, Portugal; ' Department of Agricultural Biotechnology, University of Florence, Florence, Italy
}

(Received 4 November 2008; final version received 16 March 2009)

\begin{abstract}
Phototrophic biofilm samples from an Italian wastewater treatment plant were studied in microcosm experiments under varying irradiances, temperatures and flow regimes to assess the effects of environmental variables and phototrophic biomass on capsular exopolysaccharides (CPS). The results, obtained from circular dichroism spectroscopy and High Performance Liquid Chromatography, suggest that CPS have a stable spatial conformation and a complex monosaccharide composition. The total amount present was positively correlated with the biomass of cyanobacteria and diatoms, and negatively with the biovolume of green algae. The proportion of uronic acids showed the same correlation with these taxon groups, indicating a potential role of cyanobacteria and diatoms in the removal of residual nutrients and noxious cations in wastewater treatment. While overall biofilm growth was limited by low irradiance, high temperature $\left(30^{\circ} \mathrm{C}\right)$ and low flow velocity $\left(25 \mathrm{l} \mathrm{h}^{-1}\right)$ yielded the highest phototrophic biomass, the largest amount of CPS produced, and the highest proportion of carboxylic acids present.
\end{abstract}

Keywords: phototrophic biofilms; capsular exopolysaccharides; microcosm; circular dichroism; HPLC

\section{Introduction}

Aquatic phototrophic biofilms are comprised of phototrophs (cyanobacteria and microalgae), and chemotrophs (Archaea, bacteria, fungi and protozoa). They form highly structured communities driven by light as an energy source and secrete an exopolymeric matrix that holds the biofilm together (Wimpenny et al. 2000; Sutherland 2001; Burns et al. 2004). Different from heterotrophic biofilms, whose structure, growth, dynamics and physiology have been extensively studied in field and in culture (Stoodley et al. 2002; Palmer and Stoodley 2007), phototrophic biofilms have received little attention until recently (Wolf et al. 2007). The recent increase of interest in the structure and functioning of phototrophic biofilm is related to their ecological importance and their high potential for biotechnological applications, such as wastewater treatment (Schumacher et al. 2003; Roeselers et al. 2008), bioremediation (Cohen 2002; Chaillan et al. 2006), aquaculture (Bender and Phillips 2004) and antifoulant production (Bhadury and Wright 2004).

The extracellular matrix is a key factor for the overall functionality of phototrophic biofilms. It is a highly hydrated system composed of extracellular polymeric substances (EPS), which mainly comprises polysaccharides, along with a wide variety of proteins, glycoproteins, glycolipids and nucleic acids (Stoodley et al. 2002; Chiovitti et al. 2003; Cogan and Keener
2004). Independent of the composition of EPS molecules, the matrix typically features a hydrogellike structure, which embeds the biofilm cells and determines the physico-chemical and biological properties of the whole biofilm (Mayer et al. 1999; Flemming et al. 2007).

From an ecological point of view, the matrix is the major factor for biofilm success. Its network of polymeric chains formed by intra- and intermolecular linkages provides mechanical stability such that cell positions are maintained over prolonged periods (Flemming et al. 2007). In addition, EPS and in particular capsular polysaccharides (CPS), are thought to play an important role in the attachment of cells to substrata. This allows the formation of stable microconsortia with a low expense of energy, as the existence of a stable micro-environment allows the cells to metabolise, reproduce and communicate between each other more efficiently (Decho 2000). In addition to the advantages of mechanical stability, the matrix also provides protection against heavy metals, other toxic substances and grazing by predators.

The formation of stable complexes between the biofilm matrix and metal ions gives the EPS a key role for a large range of biotechnological applications of biofilms. The presence of carboxylic groups and other anionic residues of exopolysaccharides allows the binding and accumulation of cations (De Philippis

*Corresponding author. Email: albertano@uniroma2.it 
and Vincenzini 1998), which pinpoints the potential for the exploitation of biofilms in the removal of metals from polluted waters (Mehta and Gaur 2005; De Philippis et al. 2007) and in wastewater treatment (Cohen 2002; Bender and Phillips 2004).

The species composition of the microbial biofilm community is one of the main factors that determines the composition and production of EPS (Neu 1994; Bahulikar and Kroth 2008). Chemical studies of the exopolysaccharides produced by cultured and natural populations of cyanobacteria and diatoms show that EPS are mainly complex anionic heteropolymers formed by different monosaccharides, whose proportions depend on the specific organisms. Because the biofilm community itself is a mixture of diverse microorganisms, the dependence of EPS composition on the contributing species is very complex (Flemming et al. 2007). In any case, the crucial role of community composition should always be considered in studies on biofilm EPS.

In addition to species composition, exopolymers are also strongly influenced by environmental factors, such as irradiance. The influence of irradiance levels on EPS production by cultured diatoms and cyanobacteria has been studied in some detail, and production has been closely linked to photosynthesis (Staats et al. 2000; Otero and Vincenzini 2003; Stal and Defarge 2005). On the other hand, there is little information on the effect of temperature on EPS production in mixed biofilms containing diatoms (Wolfstein and Stal 2002) and cyanobacteria (Moreno et al. 1998).

In the present investigation, a study was carried out of the CPS of phototrophic biofilms grown in a continuous flow incubator, specifically designed for studying biofilm development (Zippel and Neu 2005), using inocula collected from a wastewater treatment plant (WWTP). In accordance with a series of authors (Vincenzini et al. 1990; De Philippis and Vincenzini 1998; de Brouwer et al. 2002; Barranguet et al. 2004; Bellinger et al. 2005; Stal and Defarge 2005) 'CPS' is also used by the current authors to refer to the 'bound extracellular carbohydrates', as the exopolysaccharide fraction more intimately associated with the cells, as opposed to the 'released polysaccharides' or 'soluble extracellular carbohydrates', the solubilised mucilaginous fraction which is loosely attached to the cell surface. The effects of light intensity, temperature, water flow velocity and phototrophic biomass on the total amount and on the physico-chemical properties of the CPS were monitored.

Phototrophic biomass was estimated by its total biovolume, as the latter accounts for the high variability of shapes and dimensions of different taxa constituting biofilm communities (Stevenson 1996). One aim was detecting significant dependencies between the properties of the CPS (including the technologically relevant proportion of uronic acids) and environmental factors and the composition of the phototrophic component. The results are discussed with respect to future experimental endeavours to unravel the complex network behind whole-biofilm functionality and possible optimisation strategies for the application of phototrophic biofilms in wastewater treatment.

\section{Materials and methods}

\section{Sample collection and inoculum treatment}

Biofilm inocula were collected from the Fiumicino (Rome, Italy) WWTP on four different occasions by scraping submerged biofilms off the walls of the sedimentation tank (Table 1). Inocula for the culture study were obtained according to Guzzon et al. (2005): the samples were treated to eliminate grazers, and four aliquots of ca. $100 \mathrm{ml}$ homogeneous suspension were poured into four 51 High Density Polyethylene (HDPE) bottles, each containing 3.91 of the medium. The medium-inoculum mixture was filtered through a net (300 $\mu \mathrm{m}$ mesh) and then used to inoculate slides in the continuous flow incubator ( $72 \mathrm{~h}, 100 \mathrm{l} \mathrm{h}^{-1}$ flow rate).

Identification of phototrophs within the inocula was based on previous studies of biofilms developing in the sedimentation tank of the Fiumicino WWTP (Albertano et al. 1999; Congestri et al. 2003, 2005, 2006) and evaluated by light microscope observations.

\section{Microcosm experiments}

Inocula were grown in a prototype incubator, developed by the Department of Inland Water Research, UFZ Centre for Environmental Research (Magdeburg, Germany; Zippel and Neu 2005; Zippel et al. 2007). The incubator consisted of four separate light chambers (LC), featuring photon flux densities of 120 (abbreviated as LC120), 60 (LC60), 30 (LC30) and $15 \mu \mathrm{mol}$ photon $\mathrm{m}^{-2} \mathrm{~s}^{-1}$ (LC15). 'True light' lamps (T-8; AURALIGHT; Sweden) were used as light source to illuminate the LCs in a 16:8 h light:dark

Table 1. Inoculum sampling period, experimental conditions and labels used in the text of the performed incubator runs.

\begin{tabular}{lllcr}
\hline $\begin{array}{l}\text { Incubator } \\
\text { run }\end{array}$ & Label & $\begin{array}{l}\text { Sampling } \\
\text { month } \\
\text { (Year 2004) }\end{array}$ & $\begin{array}{c}\text { Temperature } \\
\left({ }^{\circ} \mathrm{C}\right)\end{array}$ & $\begin{array}{r}\text { Flow } \\
\text { velocity } \\
\left(\mathrm{l} \mathrm{h}^{-1}\right)\end{array}$ \\
\hline 1 & R20.25 & April & 20 & 25 \\
2 & R20.100 & June & 20 & 100 \\
3 & R30.25 & July & 30 & 25 \\
4 & R30.100 & September & 30 & 100 \\
\hline
\end{tabular}


cycle. Five litres of medium were pumped through the incubator over polycarbonate slides serving as an artificial substratum for biofilm adhesion. In addition to light intensity, four parameter combinations featuring two temperatures $\left(20\right.$ and $\left.30^{\circ} \mathrm{C}\right)$ and two flow rates $\left(25\right.$ and $1001 \mathrm{~h}^{-1}$ ) were tested (Table 1). These four incubator runs are referred to as Runs, abbreviated as eg R20.25 for the combination of $20^{\circ} \mathrm{C}$ and $251 \mathrm{~h}^{-1}$.

Biomass accumulation was estimated by light transmittance through the biofilm, comparing the incident light intensity as measured directly under the lamp with the readings of three subsurface light-sensor banks, each consisting of three diodes. A linear relation between subsurface light attenuation and biomass accumulation has been shown by Zippel et al. (2007). In this way, growth and development of the biofilms were monitored over 30 days. In the present study, biofilm samples were scraped off the polycarbonate slides for subsequent analyses when the mature stage, corresponding to an average light absorption of $90-95 \%$, had been reached.

\section{Extraction and quantification of CPS}

Mature biofilms were removed from the slides and centrifuged at 10,000 rpm for $60 \mathrm{~min}$ (J2-21 Beckman centrifuge) to concentrate the sample. The resulting pellet, comprising the microorganisms and their envelopes (namely 'capsular' [CPS] or 'bound' polysaccharides) was re-suspended in distilled water (1:10), incubated at $80^{\circ} \mathrm{C}$ for $60 \mathrm{~min}$ and then centrifuged for $15 \mathrm{~min}$ at $10,000 \mathrm{rpm}$ to remove the cells. The CPS were precipitated in ethanol $100 \%$ by centrifugation at $14,000 \mathrm{rpm}$ for $60 \mathrm{~min}$. To further purify the polymers, the resulting pellet was re-suspended in distilled water, dialysed against EDTA $(0.01 \mathrm{M})$ and $\mathrm{NaCl}(0.5 \mathrm{M})$ for $2 \mathrm{~h}$ and then against distilled water for 4 days. The extraction of the CPS was conducted following Bellezza et al. (2003). The CPS samples were lyophilised and hydrolysed ( $2 \mathrm{~N}$ trifluoroacetic acid, $120^{\circ} \mathrm{C}$ for $45 \mathrm{~min}$ ) and their monosaccharide composition quantified by means of RP-HPLC (reverse phase), using a Beckman Ultrasphere ODS column according to Vincenzini et al. (1990). The quantity of CPS extracts was estimated by the phenol-sulphuric acid method, using glucose as standard (Dubois 1956).

\section{Circular dichroism analyses}

The CPS fractions were analysed by means of circular dichroism (CD), a qualitative spectroscopic method to investigate the presence of carboxylic moieties and the potential conformational transition of polysaccharides as a function of $\mathrm{pH}$ and temperature. Measurements were performed using a Jasco Spectropolarimeter J600, equipped with quartz cells of $0.5 \mathrm{~cm}$ optical length, using original Jasco software $\left(20 \mathrm{~nm} \mathrm{~min}{ }^{-1}\right.$ scanning velocity). Preliminary analyses were performed in the UV spectral region (200-300 nm) in order to verify the extract purity and subsequently between 200 and $260 \mathrm{~nm}$ to detect the presence of carboxylic moieties.

The $\mathrm{pH}$ values were measured with the digital combined $\mathrm{pH}$ meter Amel Instruments, Model 334-B, calibrated with buffer solutions at $\mathrm{pH} 4.0$ and 8.0. The $\mathrm{pH}$ of the CPS was decreased by adding perchloric acid $\left(\mathrm{HClO}_{4}\right) 0.02 \mathrm{M}$ and increased with $\mathrm{NaOH} 0.02 \mathrm{M}$. The analyses were performed at 20 and $70^{\circ} \mathrm{C}$, respectively, using a cell holder connected to a Lauda M3 thermostat unit.

\section{Cytochemistry}

Biofilm fragments were stained with Alcian Blue (AB) and observed with light microscopy (Zeiss Axioskop), to visualise the presence of carboxylic $(\mathrm{AB} \mathrm{pH} 2.5)$ and sulphated $(\mathrm{AB} \mathrm{pH}$ 0.5) polysaccharides in cyanobacteria and microalgae (Albertano and Bellezza 2001).

\section{Phototrophic biomass}

Phototrophic biomass was estimated as the biovolume of individual taxa. Three biofilm replicates of $1 \mathrm{~cm}^{2}$ were scraped off the slides and fixed in $2 \%$ formaldehyde in $0.1 \mathrm{M}$ phosphate buffer $(\mathrm{pH} 7.2)$ at $4^{\circ} \mathrm{C}$. Preparation of samples for biovolume evaluation was carried out according to Congestri et al. (2006). The scrapings were sonicated twice for $3 \mathrm{~min}$ in a sonic water bath to disaggregate the samples. Aliquots of suspensions were diluted in phosphate buffer and allowed to settle for $24 \mathrm{~h}$ in $25 \mathrm{ml}$ counting chambers. Observations were made with an inverted Zeiss Axiovert 100 microscope. A Nikon CoolSnap digital photo-camera was used to acquire optical fields and digital images. Measurements of selected morphometric parameters were calculated manually on digital images using Adobe Photoshop version 7.0. To estimate the biovolume of single cells standardised equations proposed for the different cyanobacterial and algal shapes were used (Hillebrand et al. 1999).

\section{Statistical analyses}

Statistical analyses were carried out using the $\mathrm{R}$ language, version 2.7.1 for Mac OS X (R Core Development Team 2008), using Aabel software version 2.4.2 (Gigawiz, Tulsa, OK) for graphical representations. To quantify and describe the monosaccharide proportions obtained by High Performance Liquid Chromatography (HPLC) analysis, the proportions in each experiment were transformed to their 
corresponding ranks, with the monosaccharide with the largest proportion obtaining rank 1 , and the one with the least proportion the highest rank. To integrate the results from all experiments, the mean and the standard deviation (SD) of the ranks of each monosaccharide across the experiments were calculated, and rounded to integer values, to obtain an overall ranking.

To calculate the similarities between the monosaccharide compositions obtained in each experiment the centred log-ratios (CLR) of the monosaccharide proportions were calculated as

$$
\mathrm{CLR}_{i}=\log \frac{x_{i}}{G(x)}
$$

with $G(x)$ being the geometric mean of the proportions $x_{i}$, using routines from the R-package compositions (van den Boogaart and Tolosana-Delgado 2008). The dissimilarity of two compositions was quantified by the Euclidean distance between the CLRs of each composition. On the basis of the resulting dissimilarity matrix, hierarchical clustering analysis was performed using the average linkage method.

Correlations were quantified by Pearson's $r$, using log-transformed data and CLRs. Given the presence of missing data, the effects of the environmental factors were not assessed by ANOVA. Instead, the relevant paired differences between data from different LCs and Runs were computed and discussed. The possibility of a significant effect was suggested if all observed differences were clearly different from zero and had the same, positive or negative, sign.

\section{Results}

\section{Phototrophic diversity of the inocula}

The diversity of phototrophs within the inocula collected on the different sampling occasions was expressed as taxon numbers (Supplementary Table 1) [Supplementary material is available via a multimedia link on the online article webpage]. The phototrophic component consisted primarily of cyanobacteria, diatoms and green algae, with one xanthophyte and one euglenophyte. Taxon numbers were generally low and stable, yielding up to 8 cyanobacterial taxa for June and July, and 15 diatom taxa in April and September. Chlorophytes consisted of five (April, June and July) or six (September) taxa.

\section{Biofilm development}

Only biofilms grown under 60 and $120 \mu$ mol photon $\mathrm{m}^{-2} \mathrm{~s}^{-1}$ reached the mature stage of development by day 30 . Here, the polycarbonate slides were uniformly colonised with biofilms of ca. $1 \mathrm{~mm}$ thickness, exhibiting a dark green coloration and seemingly gelatinous consistency. The cultures grown under $30 \mu \mathrm{mol}$ photon $\mathrm{m}^{-2} \mathrm{~s}^{-1}$ reached the active phase (average light absorption $=50 \%$ ) of development in R20.25 and R30.100, and remained at the initial stage (average light absorption $=5 \%$ ) in R20.100 and $\mathrm{R} 30.25$. Cultures grown under $15 \mu \mathrm{mol}$ photon $\mathrm{m}^{-2}$ $\mathrm{s}^{-1}$ did not show any substantial growth throughout the 30 day incubation period. As these conditions thus yielded insufficient biomass for subsequent processing, all further analyses were limited to samples obtained from mature LC120 and LC60 cultures.

\section{Amounts of exopolysaccharide}

Figure 1 shows the total amount of CPS, expressed as $\mathrm{mg}$ glucose equivalent per $\mathrm{cm}^{-2}$ surface area, ranging between $(47 \pm 8) \times 10^{-4} \mathrm{mg} \mathrm{cm}^{-2}$ in $\mathrm{R} 30.100$ LC120 and $(783 \pm 46) \times 10^{-4} \mathrm{mg} \mathrm{cm}^{-2}$ in R30.25LC60, respectively. Table 2 shows the effects of environmental parameters on the amount of CPS. The comparison of the amounts in R20.25 and R30.25 showed an increase of CPS with temperature in both studied pairs. The other factors yielded no coherent evidence for an effect on CPS.

\section{Circular dichroism analyses}

Supplementary Figure 1 [Supplementary material is available via a multimedia link on the online article webpage] shows the $\mathrm{CD}$ spectra of the capsular polysaccharide extracts. In all cases, an ellipticity typical for carboxylic moieties was witnessed between 200 and $250 \mathrm{~nm}$, while no effect was observed above $260 \mathrm{~nm}$, indicating the complete removal of proteins from the extracts. Variations in $\mathrm{pH}$ and temperature did not elicit clear changes of the CD spectra, suggesting a stable polymeric conformation of the CPS.

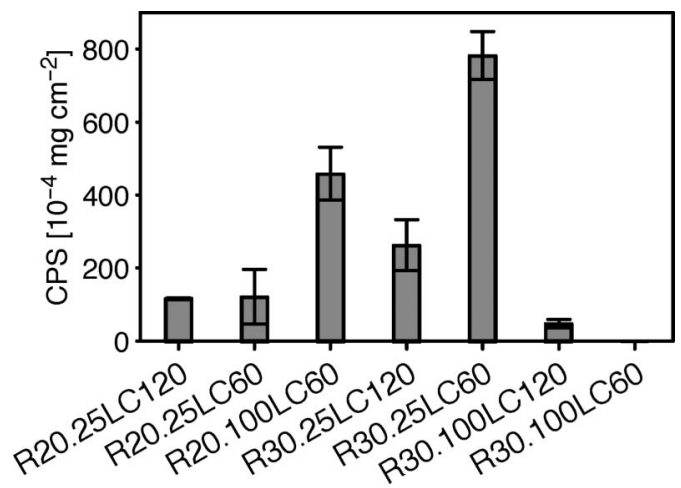

Figure 1. Concentration of the CPS $\left(10^{-4} \mathrm{mg} \mathrm{cm}^{-2}\right)$ for all analysed samples. 
Table 2. Differences in capsular exopolysaccharides (CPS), total uronic acids (TUrAc) and total phototrophic biovolume $\left(V_{\text {Total }}\right)$ between experiments featuring common changes in environmental factors.

\begin{tabular}{|c|c|c|c|}
\hline & $\begin{array}{c}\text { CPS } \\
\left(10^{-4} \mathrm{mg} \mathrm{cm}^{-2}\right)\end{array}$ & TUrAc $(\%)$ & $\left(10^{6} \mu \mathrm{m}^{3} \mathrm{~cm}^{-2}\right)$ \\
\hline \multicolumn{4}{|l|}{ Light } \\
\hline R20.25LC120-R20.25LC60 & $-5 \pm 53$ & 1.62 & $-93 \pm 41$ \\
\hline R30.25LC120-R30.25LC60 & $-520 \pm 68$ & -2.17 & $-402 \pm 61$ \\
\hline R30.100LC120-R30.100LC60 & $\overline{\mathrm{ND}}$ & -1.84 & $248 \pm 127$ \\
\hline \multicolumn{4}{|l|}{ Temperature } \\
\hline R20.25LC120-R30.25LC120 & $-146 \pm 49$ & -1.57 & $-509 \pm 40$ \\
\hline R20.25LC60-R30.25LC60 & $-661 \pm 70$ & -5.36 & $-819 \pm 62$ \\
\hline R20.100LC60-R30.100LC60 & ND & -2.75 & $128 \pm 141$ \\
\hline \multicolumn{4}{|l|}{ Flow velocity } \\
\hline R20.25LC60-R20.100LC60 & $-342 \pm 73$ & 2.69 & $-582 \pm 84$ \\
\hline R30.25LC120-R30.100LC120 & $216 \pm 50$ & 1.51 & $55 \pm 125$ \\
\hline R30.25LC60-R30.100LC60 & ND & 1.84 & $705 \pm 66$ \\
\hline
\end{tabular}

\section{Monosaccharide composition}

All capsular polysaccharide samples analysed by means of HPLC contained various proportions of seven neutral monosaccharides and two uronic acids (Table 3). Across seven experiments, glucose and mannose were the dominant components with a median proportion of $27.8 \%$ and $17.5 \%$, respectively. Both ranked first and second in most experiments, as was expressed by rank $1 \pm 1$ (rounded mean \pm SD) for glucose and rank $2 \pm 1$ for mannose. They were trailed by rhamnose, galactose and fucose, showing median proportions of $\sim 10 \%$. It is interesting to notice the relatively large variation in the ranking of galactose, ranking fourth on average with a SD of three ranks. Xylose and arabinose both exhibited median proportions around 5\%. Between the two uronic acids, glucuronic acid showed clearly higher proportions and rankings $(6.0 \%$ median, average rank 6) than galacturonic acid with $2.2 \%$ median proportion and being ranked last in all experiments, as was also indicated by the zero variance of its rank $(9 \pm 0$, ref. Table 3$)$.

Figure 2 shows the result of the clustering analysis of the monosaccharide compositions of the seven performed experiments, together with a heatmap depicting the monosaccharide proportions obtained in each experiment. Three groups of monosaccharide profiles could be distinguished and are marked by rectangles in Figure 2: one group features the three samples placed at the bottom of the heatmap, R20.25LC120, R30.25LC120 and R30.25LC60. This cluster was marked by a strong dominance of glucose, which reached its three maximum proportions (all $>$ $28 \%$ ) in this cluster. The second cluster joined R20.25LC60, R30.100LC120 and R30.100LC60, and distinguished itself from the former cluster by elevated proportions of galactose and less glucose. The R20.100LC60 sample was distinct from the other two
Table 3. Monosaccharide composition of CPS fractions extracted from mature biofilms.

\begin{tabular}{lcc}
\hline Sugar & Median prop. & Rank \\
\hline Glucose & 27.8 & $1 \pm 1$ \\
Arabinose & 5.0 & $7 \pm 1$ \\
Xylose & 5.2 & $6 \pm 2$ \\
Gluc. acid & 6.0 & $6 \pm 1$ \\
Fucose & 9.7 & $5 \pm 1$ \\
Galactose & 10.6 & $4 \pm 3$ \\
Rhamnose & 11.5 & $4 \pm 2$ \\
Mannose & 17.5 & $2 \pm 1$ \\
Gal. acid & 2.2 & $9 \pm 0$ \\
\hline
\end{tabular}

Median proportions are expressed as mol \%. Ranks are given as mean $\pm \mathrm{SE}$ over seven experiments rounded to integer values.

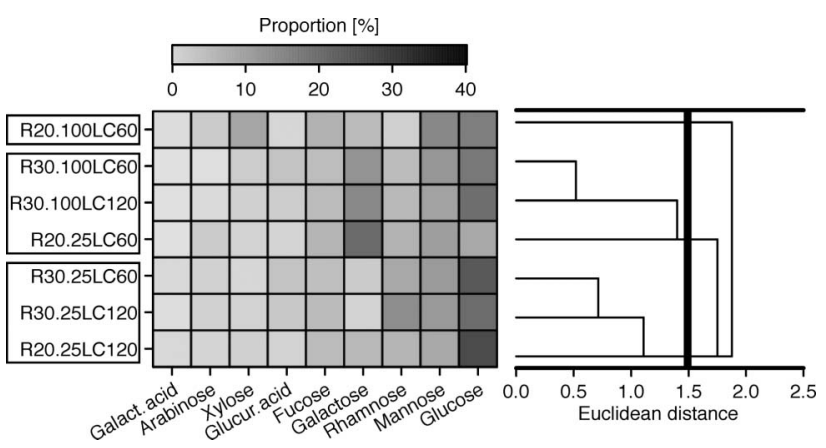

Figure 2. Heatmap of the proportions of monosaccharides and dendrogram of the monosaccharide composition. Monosaccharides are ordered by their median values (Supplementary Table 2), while Runs are ordered according to the cluster tree. Cutting the dendrogram at a euclidean distance of 1.5 (grey bar, right panel), three clusters are obtained which are marked by the rectangles around the run labels (left panel).

clusters mainly due to the high proportion of xylose ranking third with $14.8 \%$, far above its median value. Rhamnose proportions in turn were extremely low in this sample $(5 \%$, rank 7$)$. This clustering of the monosaccharides did not reveal a clear effect by any 
of the environmental parameters. The high similarity of the R30.25and R30.100 samples, respectively, suggested a major effect of the inoculum and/or the inoculation process used in each incubator run.

\section{Total proportion of uronic acids}

In Figure 3A the total proportion of uronic acids (TUrAc) in each experiment is shown. Values ranged between $7.5 \%$ in $\mathrm{R} 20.25 \mathrm{LC} 120$ and $\mathrm{R} 30.100 \mathrm{LC} 120$ and $11.2 \%$ in R30.25LC60. The impact of environmental factors is assessed in Table 2. For the experiments performed at $30^{\circ} \mathrm{C} \quad(\mathrm{R} 30.25$ and R30.100), there was an apparent decrease of TUrAc with light intensity, ie R30.25LC60 showed larger proportions of TUrAc than R30.25LC120, and likewise for R30.100. However, this was not the case for R20.25, hence a consistent effect of light was not apparent. Concerning the two other parameters, there were indications that TUrAc increased with temperature and decreased at higher flow velocity, as all possible comparisons showed consistent trends.

\section{Cytochemistry}

$\mathrm{AB} \mathrm{pH} 2.5$ staining revealed the presence of carboxylic groups in the envelopes of all chroococcalean and oscillatorialean cyanobacteria and in the diatom Diadesmis confervacea, while no reaction was elicited by any of the featured green algae (Supplementary Table 2) [Supplementary material is available via a multimedia link on the online article webpage]. Staining with AB at $\mathrm{pH} 0.5$ indicated the presence of sulphated residues in the exopolysaccharides of the coccoid cyanobacterium Chroococcus sp. and of D. confervacea. No sulphated residues were detected either in the unicellular cyanobacterium Synechocystis sp., or in any of the oscillatorialeans and the green algae.

\section{Phototrophic biovolumes}

Figure 3B shows the total phototrophic biovolumes $\left(V_{\text {Total }}\right)$ and the proportions of the different phototrophic taxa. The highest $V_{\text {Total }}$ was recorded in R30.25LC60 with $(1032 \pm 39) \times 10^{6} \mu \mathrm{m}^{3} \mathrm{~cm}^{-2}$ and the minimum value was observed in R20.25LC120

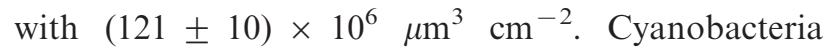
dominated the samples of all runs except for R20.25, with biovolume $\left(V_{\text {Cyano }}\right)$ varying between $(15 \pm 1) \times 10^{6}$ and $(779 \pm 24) \times 10^{6} \mu \mathrm{m}^{3} \mathrm{~cm}^{-2}$ in R20.25LC60 and R30.25LC60, respectively. Diatoms were only present in R20.100 and R30.25, showing a peak biovolume $\left(V_{\text {Diat }}\right)$ of $(225 \pm 17) \times 10^{6} \mu \mathrm{m}^{3}$ $\mathrm{cm}^{-2}$ in R30.25LC60. This value was substantially higher than the other two non-zero values of $V_{\text {Diat }}$,

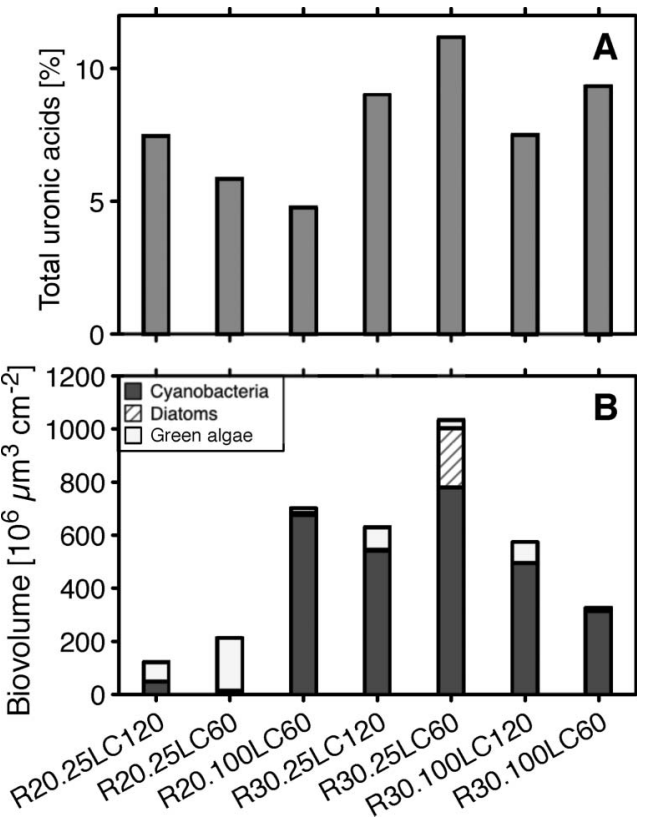

Figure 3. Quantitative observations for all analysed samples. A: Total proportion of uronic acids (mol \%). B: Total phototrophic biovolumes $\left(10^{6} \mu \mathrm{m}^{3} \mathrm{~cm}^{-2}\right)$ of mature biofilms and proportions of the major taxonomic groups.

$\left(4 \times 10^{6}\right.$ and $\left.9 \times 10^{6} \mu \mathrm{m}^{3} \mathrm{~cm}^{-2}\right)$. Green algae biovolumes $\left(V_{\text {Green }}\right)$ were non-zero in all runs, yielding at least $(13 \pm 1) \times 10^{6} \mu \mathrm{m}^{3} \mathrm{~cm}^{-2}(\mathrm{R} 30.100 \mathrm{LC} 60)$. Green algae dominated in R20.25 communities, reaching an overall maximum of $(199 \pm 32) \times 10^{6} \mu \mathrm{m}^{3} \mathrm{~cm}^{-2}$ in R20.25LC60.

Figure $4 \mathrm{~A}-\mathrm{D}$ shows the $\log -\log$ scatter plots of the total amount of CPS vs $V_{\text {Total, }} V_{\text {Cyano, }}, V_{\text {Diat }}$ and $V_{\text {Green. }}$ From visual inspection of the plot, two influential points were identified and marked with an open square (R30.25LC120) and open circle (R30.100LC120). Both samples were characterised by the dominance of cyanobacteria together with a considerable biovolume of green algae (Figure 3B), but CPS of R30.100LC120 had an extremely low value. A correlation analysis of the remaining points (solid dots) showed a significant correlation between CPS and $V_{\text {Total }}(r=0.98, p=0.019)$ and CPS and $V_{\text {Cyano }}$ $(r=0.98, p=0.018)$. The correlation between CPS and $V_{\text {Diat }}$ was not significant, due to the low number of points. Finally, there was an anti-correlation of CPS and $V_{\text {Green }}(r=-0.99, p=0.01)$ with diatom biovolume (rho $=0.91, p=0.005$ ). The bottom row of Figure $4(\mathrm{E}-\mathrm{H})$ exhibits CLR-CLR scatterplots of the proportions of TUrAc $v s$ the logarithm of $V_{\text {Total }}$ and the CLR of the proportions of cyanobacteria, diatoms and green algae. Here, the R20.100LC60 sample, whose monosaccharide composition was very different from the other samples (Figure 2) was identified as an influential point. Excluding this point, TUrAc was 

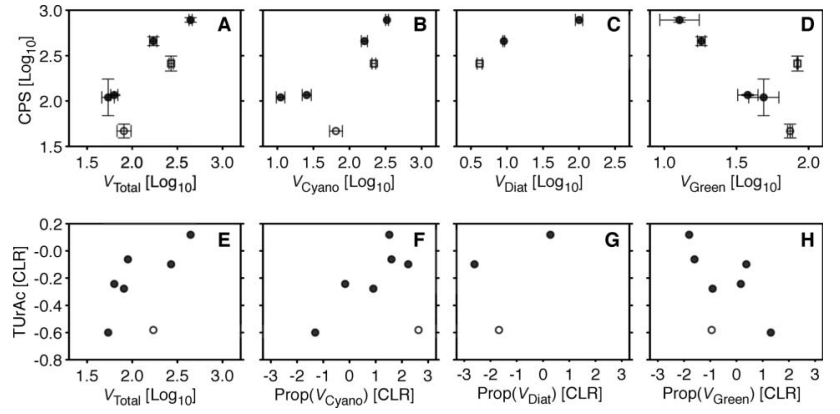

Figure 4. Relations of capsular polysaccharide properties with phototrophic biovolumes. Top row A-D: Log-log scatterplots of CPS and total phototrophic biovolume $\left(V_{\text {Total }}\right)$, and biovolumes of cyanobacteria $\left(V_{\text {Cyano }}\right)$, diatoms ( $\left.V_{\text {Diat }}\right)$ and green algae $\left(V_{\text {Green }}\right) . \square=$ the influential sample R30.25LC120; O = the R30.100LC120 sample. Bottom row, E-H: CLR-Log/CLR scatterplots of total uronic acids (TUrAc), vs total phototrophic biovolume $\left(V_{\text {Total }}\right)$ and the CLR of the proportions (Prop) of $V_{\text {Cyano }}, V_{\text {Diat }}$, and $V_{\text {Green }}$. $\mathrm{O}=$ the R20.100LC60 sample (see text for further explanations).

marginally correlated to $V_{\text {Total }}(r=0.8, p=0.056)$. A significant correlation was given with the proportion of $V_{\text {Cyano }}(r=0.85, p=0.03)$ and a marginally significant anti-correlation given with $V_{\text {Green }}(r=-0.8$, $p=0.055)$.

\section{Discussion}

In the present study, the amount and the physicochemical properties of CPS of phototrophic biofilms sampled from an Italian WWTP and cultured in a microcosm under different conditions of light intensity, temperature and water flow velocity were assessed. Simultaneously, the biovolumes of phototrophs were analysed to assess the dependency of CPS on taxon composition. One aim was to unravel the most important interactions in the network consisting of matrix properties, environmental factors and phototrophic species biomass, in order to contribute to the deeper understanding of the overall ecological performance and the biotechnological potential of phototrophic biofilms.

The strongest relations evidenced in the experiments involved the amount of CPS, which was correlated with the total phototrophic biovolume, ie the estimated phototrophic biomass (Figure 4). More specifically, as the highest total biovolumes were correlated with high biovolumes of cyanobacteria $\left(V_{\text {Cyano }}\right)$ and diatoms $\left(V_{\text {Diat }}\right)$, and the overall maximum values of CPS, $V_{\text {Cyano }}$ and $V_{\text {Diat }}$ were all reached in R30.25LC60, the amount of CPS in mature biofilms appeared to be significantly related to these two taxa. In contrast, the amount of CPS was generally low in samples with high biovolumes of green algae, suggesting a reduced importance of the latter for CPS abundance. Exopolysaccharide production is known to be related to both the phototrophic and the heterotrophic components of biofilm communities (Decho 1990). The heterotrophic fraction was not evaluated in this work. However, the consistency of the phototrophic contribution (up to $60 \%$ ) has been shown in parallel experiments (Zippel and Neu 2005). The present results therefore stress the already known importance of the total phototrophic component for CPS production, and go further by identifying cyanobacteria and diatoms as the key sub-components in this process. Significant relationships have been reported only between capsular or bound polysaccharide production and total phototrophic biomass for natural and cultured phototrophic biofilms as for diatom-dominated communities (Bellinger et al. 2005; Stal and Defarge 2005) and algal microphytobenthos (Barranguet et al. 2005). In the present study, the biovolume data of the phototrophic multispecies cultured biofilms allowed identification for the first time of the major contribution of two phototrophic taxon groups to CPS quantities.

A number of cyanobacteria and one diatom species were also recognised as the main producers of the high proportions of carboxylic groups in the CPS. The presence of these groups, embedded in the chiral saccharide moieties was found in all CD spectra, exhibiting an ellipticity in the spectral region between 200 and $240 \mathrm{~nm}$ (Supplementary Figure 1). The HPLC studies confirmed the presence of two uronic acids, galacturonic and glucuronic acid, in the heteropolymeric matrix, along with eight neutral monosaccharides (Figure 2). As in the case of the total amount of CPS, the quantitative assessment of the TUrAc revealed a significant correlation with the proportion of cyanobacteria and diatoms, and an anti-correlation with the proportion of green algae (Figure $4 \mathrm{E}-\mathrm{H}$ ). This is confirmed by the results of $\mathrm{AB}$ staining experiments, which detected the presence of carboxylic and sulphate groups in the envelopes of cyanobacteria and diatoms, but not in green algae (Supplementary Table 2). This is in accordance with previous studies of natural biofilms from the same sampling site (Congestri et al. 2006), indicating that the results obtained from the featured cultured biofilms could be extrapolated to phototrophic biofilms in their natural environment.

The complex monosaccharide composition of the CPS, in which glucose and mannose were the dominant sugars, was similar to that of exopolysaccharides synthesised by a variety of cyanobacteria (De Philippis and Vincenzini 1998; Bellezza et al. 2003, 2005, 2006; Parikh and Madamwar 2006) and diatoms (Staats et al. 1999; de Brouwer et al. 2002; Underwood et al. 2004; De Philippis et al. 2005; Abdullahi et al. 2006; Hanlon et al. 2006; Bahulikar and Kroth 2008). 
Even though the proportions of the monosaccharides did not vary by large numbers, the performance of hierarchical cluster analysis revealed a clear pattern of similarities between the different samples (Figure 2): the closest similarities between any two samples were observed for the two R30.25 and R30.100 samples, respectively, suggesting that the common inoculum played a critical role in the determination of the monosaccharide composition. This was an apparent contradiction to the authors' observation that the different samples of natural communities all had a low biodiversity with stable taxon numbers (Congestri et al. 2003, 2006; Guzzon et al. 2005). However, DGGE analysis of $16 \mathrm{~S}$ and 18S rRNA gene fragments in parallel studies performed by Roeselers et al. (2006) also showed that the community composition in the cultured biofilm varied in spite of unchanged taxon numbers. In their study, these authors discussed the hypothesis that the observed variations might be introduced by random variations in the course of the experiment, eg by turbulence, or be due to nonlinear effects, ie chaotic dynamics, in biofilm development. In order to reduce the uncontrolled amount of variability in future microcosm experiments on phototrophic biofilms, the assessment of the species composition by taxon numbers could be complemented and fine-tuned by other techniques, eg quantitative DNA-based molecular studies.

As in the work by Roeselers et al. (2006), the masking of environmental effects by variations in the species community interfered with the objective of identifying significant effects of light intensity, temperature and flow velocity. However, the present study suggested some tendencies, which are in line with the work of other authors. The strongest effect elicited by light intensity was the reduction of growth at lower intensity, severely limiting the latter at the lowest intensity. This is in accordance with other experiments performed with the same inocula and the same incubator prototype (Roeselers et al. 2006; Zippel et al. 2007). According to the observed difference between corresponding samples (Table 2), the amount of CPS increased with temperature. This has been reported earlier by work of Staats et al. (2000) and Wolfstein and Stal (2002) on the EPS content of benthic diatoms. As these authors suggested, this temperature-dependent increase could be related to an increase in photosynthesis rates, given the demonstrated direct relationship between the production of EPS and oxygenic photosynthesis. The TUrAc followed the same tendency for temperature and apparently decreased with flow velocity.

Comparing $\mathrm{CD}$ spectra for samples exposed to different temperatures and $\mathrm{pH}$ values did not show any variation elicited by these factors (Supplementary Figure 1). This result is in agreement with observations made on phototrophic biofilms naturally developing on the sedimentation tank walls of the Fiumicino WWTP (Congestri et al. 2006). The stability of the conformation against changes in temperature and $\mathrm{pH}$ could be explained by a random arrangement of these polymers in solution, and the presence of a disordered sequence of saccharide units in the biopolymer chain (Cesaro et al. 1990). The 'random-coil' polymeric conformation was also demonstrated in previous studies on chemically similar polysaccharides produced by some cyanobacteria (Cesaro et al. 1990; Bellezza et al. 2003, 2005, 2006) and by the green macroalga Ulva sp. (Paradossi et al. 2002).

\section{Conclusions}

The CPS of cultured phototrophic biofilms were found to be composed of at least eight monosaccharides arranged in a disordered sequence of saccharide units and in a spatially random fashion. Glucose dominated in all samples followed by mannose independent of the biomass of the constituent taxa.

The relevant role of cyanobacteria and diatoms in the production of large amounts of CPS and high proportions of uronic acids was highlighted by the contribution of these taxon groups to the phototrophic biofilm biomass.

The effects of environmental parameters on phototrophic biomass and CPS properties can be overridden by variability in the biofilm species composition. To better understand environmental impacts, future studies should tightly control the shift in diversity and abundance of the taxa involved at all biofilm developmental stages.

Along with high light intensity as a key environmental factor for the development of phototrophic biofilms, higher temperatures enhance the amount of CPS and the proportion of uronic acids up to $11 \%$, making these communities useful for water treatment in open systems in the Mediterranean area.

\section{Acknowledgements}

The authors gratefully acknowledge Dr NTW Ellwood for constructive criticism of the manuscript. This research was partly conducted within the framework of EU project PHOBIA (QLK3-CT2002-01938). A. Bohn acknowledges support by the Fundação para a Ciência e a Tecnologia (Portugal) through fellowship SFRH/BPD/25967/2005.

\section{References}

Abdullahi AS, Underwood GJC, Gretz MR. 2006. Extracellular matrix assembly in diatoms (Bacillariophyceae). Environmental effects on polysaccharide synthesis in the model diatom, Phaeodactylum tricornutum. J Phycol 42:363-378. 
Albertano P, Bellezza S. 2001. Cytochemistry of cyanobacterial exopolymers in biofilms from Roman hypogea. Nova Hedwigia 123:501-518.

Albertano P, Congestri R, Shubert LE. 1999. Cyanobacterial biofilms in sewage treatment plants along the Tyrrhenian coast (Mediterranenan Sea), Italy. Arch Hydrobiol Suppl Algol Stud 94:13-24.

Bahulikar RA, Kroth PG. 2008. The complex extracellular polysaccharides of mainly chain-forming freshwater diatom species from epilithic biofilms. J Phycol 44:1465-1475.

Barranguet C, Veuger B, van Beusekom SAM, Marvan P, Sinke JJ, Admiraal W. 2005. Divergent composition of algal-bacterial biofilms developing under various external factors. Eur J Phycol 40:1-8.

Barranguet C, van Beusekom SAM, Veuger B, Neu TR, Manders EMM, Sinke JJ, Admiraal W. 2004. Studying undisturbed autotrophic biofilms: still a technical challange. Aquat Microb Ecol 34:1-9.

Bhadury P, Wright PC. 2004. Exploitation of marine algae: biogenic compounds for potential antifouling applications. Planta 219:561-578.

Bellezza S, Paradossi G, De Philippis R, Albertano P. 2003. Leptolyngbya strains from Roman hypogea: cytochemical and physico-chemical characterisation of exopolysaccharides. J Appl Phycol 15:193-200.

Bellezza S, Albertano P, De Philippis R, Paradossi G. 2005. Exopolysaccharides in cyanobacterial biofilms from Roman catacombs. Arch Hydrobiol Algol Stud 117:117132.

Bellezza S, De Philippis R, Paradossi G, Albertano P. 2006. Exopolysaccharides of two cyanobacterial strains from Roman hypogea. Geomicrobiol J 23:301-310.

Bellinger BJ, Abdullahi AS, Gretz MR, Underwood GJC. 2005. Biofilm polymers: relationship between carbohydrate biopolymers from estuarine mudflats and unialgal cultures of benthic diatoms. Aquat Microb Ecol 38:169180.

Bender J, Phillips P. 2004. Microbial mats for multiple applications in aquaculture and bioremediation. Bioresour Technol 94:229-238.

Burns BP, Goh F, Allen M, Neilan BA. 2004. Microbial diversity of extant stromatolites in the hypersaline marine environment of Shark Bay, Australia. Environ Microbiol 6:1096-1101.

Cesaro A, Liut G, Bertocchi C, Navarini L, Urbani R. 1990. Physico-chemical properties of the exocellular polysaccharide from Cyanospira capsulata. Int J Biol Macromol 12:79-84.

Chaillan F, Gugger M, Saliot A, Coute A, Oudot J. 2006. Role of cyanobacteria in the biodegradation of crude oil by a tropical cyanobacterial mat. Chemosphere 62:15741582.

Chiovitti A, Bacic A, Burke J, Wetherbee R. 2003. Heterogeneous xylose-rich glycans are associated with extracellular glycoproteins from the biofouling diatom Craspedosauros australis (Bacillariophyceae). Eur J Phycol 39:543-554.

Cogan NG, Keener JP. 2004. The role of the biofilm matrix in structural development. Math Med Biol 21:147-166.

Cohen Y. 2002. Bioremediation of oil by marine microbial mats. Int Microbiol 5:189-193.

Congestri R, Sangiorgi VC, Albertano P. 2003. Cytomorphology and distribution of periphytic cyanobacteria in one Italian WWTP. Arch Hydrobiol Algol Stud 109:185195.
Congestri R, Cox EJ, Cavacini P, Albertano P. 2005. Diatoms (Bacillariophyta) in phototrophic biofilms colonising an Italian wastewater treatment plant. Diatom Res 20:241-255.

Congestri R, Di Pippo F, De Philippis R, Paradossi G, Albertano P. 2006. Seasonal succession of phototrophic biofilms in an Italian wastewater treatment plant: biovolume, spatial structure and exopolysaccharides. Aquat Microb Ecol 45:301-312.

de Brouwer JFC, Wolfstein K, Stal LJ. 2002. Physical characterization and diel dynamics of different fractions of extracellular polysaccharides in an axenic culture of a benthic diatom. Eur J Phycol 37:37-44.

De Philippis R, Vincenzini M. 1998. Exocellular polysaccharides from cyanobacteria and their possible applications. FEMS Microbiol Rev 22:151-175.

De Philippis R, Paperi R, Sili C. 2007. Heavy metal sorption by released polysaccharides and whole cultures of two exopolysaccharide-producing cyanobacteria. Biodegradation 18:181-187.

De Philippis R, Faraloni C, Sili C, Vincenzini M. 2005. Populations of exopolysaccharide-producing cyanobacteria and diatoms in the mucilaginous benthic aggregates of the Tyrrhenian Sea (Tuscan Archipelago). Sci Total Environ 353:360-368.

Decho AW. 1990. Microbial exopolymers secretions in ocean environments: their role(s) in food webs and marine processes. Oceanogr Mar Biol Ann Rev 28:73-153.

Decho AW. 2000. Microbial biofilms in intertidal systems: an overview. Cont Shelf Res 20:1257-1273.

Dubois M. 1956. Colorimetric method for determination of sugars and related substances. Anal Chem 28:350-356.

Flemming HC, Neu TR, Wozniak DJ. 2007. The EPS matrix: the 'house of biofilm cells'. J Bacteriol 189:7945-7947.

Guzzon A, Congestri R, Albertano P. 2005. Light-induced changes in photosynthesis and structure of cyanobacterial cultured biofilms from an Italian wastewater treatment plant. Arch Hybrobiol Algol Stud 117:223-238.

Hanlon ARM, Bellinger B, Haynes K, Xiao G, Hofman TA, Gretz MR, Ball AS, Osborn AM, Underwood GJC. 2006. Dynamics of extracellular polymeric substance (EPS) production and loss in an estuarine, diatomdominated, microalgal biofilm over a tidal emersionimmersion period. Limnol Oceanogr 51:79-93.

Hillebrand H, Dürselen CD, Kirschtel D, Pollingher U, Zohary T. 1999. Biovolume calculation for pelagic and benthic microalgae. J Phycol 35:403-424.

Mayer C, Moritz R, Kirschner C, Borchard W, Maibaum R, Wingender J, Flemming HC. 1999. The role of intermolecular interactions: studies on model systems for bacterial biofilms. Int J Biol Macromol 26:3-16.

Mehta SK, Gaur JP. 2005. Use of algae for removing heavy metals ions from wastewater: progress and prospects. Crit Rev Biotechnol 25:113-152.

Moreno J, Vargas MA, Olivares H, Rivas J, Guerrero GM. 1998. Exopolysaccharide production by the cyanobacterium Anabaena sp. ATCC 33047 in batch and continuous culture. J Biotechnol 60:175-182.

Neu TR. 1994. Biofilms and microbial mats. In: Krumbein WE, Paterson DM, Stal LJ, editors. Biostabilization of sediments. Oldenburg, Germany: BIS Verlag. p. 9-15.

Otero A, Vincenzini M. 2003. Extracellular polysaccharide synthesis by Nostoc strains as affected by $\mathrm{N}$ source and light intensity. J Biotechnol 102:143-152.

Palmer RJ, Stoodley P. 2007. Biofilms 2007: broadened horizons and new emphases. J Bacteriol 189:7948-7960. 
Paradossi G, Cavalieri F, Chiessi E. 2002. A conformational study on the algal polysaccharide ulvan. Macromolecules 35:6404-6411.

Parikh A, Madamwar D. 2006. Partial characterization of extracellular polysaccharides from cyanobacteria. Bioresour Technol 97:1822-1827.

R Development Core Team. 2008. R: A language and environment for statistical computing. R Foundation for Statistical Computing, Vienna, Austria. Available from: http://www.R-project.org. Last accessed on 30 June 2008.

Roeselers G, van Loosdrecht MCM, Muyzer G. 2008. Phototrophic biofilms and their potential applications. J Appl Phycol 20:227-235.

Roeselers G, Zippel B, Staal M, van Loosdrecht MCM, Muyzer G. 2006. On the reproducibiltity of microcosm experiments-different community composition in parallel phototrophic biofilm microcosms. FEMS Microbiol Ecol 58:169-178.

Schumacher G, Blume T, Asekuolov I. 2003. Bacteria reduction and nutrient removal in small wastewater treatment plants by an algal biofilm. Water Sci Technol 47:195-202.

Staats N, de Winder B, Stal LJ, Mur LR. 1999. Isolation and characterization of extracellular polysaccharides from the epipelic diatoms Cylindrotheca closterium and Navicula salinarum. Eur J Phycol 34:161-169.

Staats N, Stal LJ, de Winder B, Mur LR. 2000. Oxygenic photosynthesis as a driving process in exopolysaccharide production in benthic diatoms. Mar Ecol Prog Ser 193:261-269.

Stal LJ, Defarge.2005. Structure and dynamics of exopolymers in an intertidal diatom biofilm. Geomicrobiol J 22:341-352.

Stevenson RJ. 1996. An introduction to algal ecology in freshwater benthic habitats. In: Stevenson RJ, Bothwell ML, Lowe RL, editors. Algal ecology-freshwater benthic ecosystems. San Diego (CA): Academic Press. p. 321340 .
Stoodley P, Sauer K, Davies G, Costerton JW. 2002. Biofilms as complex differentiated communities. Annu Rev Microbiol 56:187-209.

Sutherland IW. 2001. Biofilm exopolysaccharides: a strong and sticky framework. Microbiology 147:3-9.

Underwood GJC, Boulcott M, Raines CA, Waldron K. 2004. Environmental effects on exopolymer production by marine benthic diatoms: dynamics, changes in composition, and pathways of production. J Phycol 40:293-304.

van den Boogaardt KG, Tolosana-Delgado R. 2008. 'Compositions': a unified R package to analyze compositional data. Comp Geosci 34:320-338.

Vincenzini M, De Philippis R, Sili C, Materassi R. 1990. Studies on exopolysaccharide release by diazotrophic batch cultures of Cyanospira capsulata. Appl Microbiol Biotechnol 34:392-396.

Wimpenny J, Manz W, Szewzyk U. 2000. Heterogeneity in biofilms. FEMS Microbiol Rev 24:661-671.

Wolf G, Picioreanu C, van Loosdrecht MCM. 2007. Kinetic modeling of phototrophic biofilms: the PHOBIA model. Biotechnol Bioeng 97:1064-1079.

Wolfstein K, Stal LJ. 2002. Production of extracellular polymeric substances (EPS) by benthic diatoms: effect of irradiance and temperature. Mar Ecol Prog Ser 236:13-22.

Zippel B, Neu TR. 2005. Growth and structure of phototrophic biofilms under controlled light conditions. Water Sci Technol 52:203-209.

Zippel B, Rijstenbil J, Neu TR. 2007. A flow-lane incubator for studying freshwater and marine phototrophic biofilms. J Microbiol Methods 70:336-345. 